\title{
Association between Fever and Primary Tooth Eruption: A Systematic Review and Meta-analysis
}

\author{
${ }^{1}$ Mariana A Nemezio, ${ }^{2}$ Katharina MH De Oliveira, ${ }^{3}$ Priscilla C Romualdo, ${ }^{4}$ Alexandra M Queiroz \\ ${ }^{5}$ Francisco WG Paula-e-Silva, ${ }^{6}$ Raquel AB Silva, ${ }^{7}$ Erika C Küchler
}

\begin{abstract}
Aim: To perform a systematic review and meta-analysis to establish if fever is associated with primary tooth eruption.

Materials and methods: Literature searches involved Pubmed, MEDLINE, Web of Science, Scopus and Cochrane. The potentially relevant studies had the full text analyzed. Only studies concerning fever during eruption period of primary tooth in humans were included. Papers in non-English language, and papers that included syndromic patients or patients with any disease were excluded. The meta-analyses were performed with Review Manager (version 5.3). Only studies that reported the results as dichotomous data were analyzed with CochranMantel-Haenszel test in meta-analysis function of Review Manager 5.3. The fixed-effects model was used to evaluate the association between tooth eruption and fever.
\end{abstract}

Results: Search identified 83 potential studies. After exclusion of the duplicated studies, or were not related to the criteria of inclusion only 6 studies were selected for the systematic review. In the overall meta-analysis, no association was found [OR = $1.32(0.88-1.96)]$ between fever and primary tooth eruption. However, in the subgroup analysis, when the method used to measure fever was the rectal temperature there was an association [OR $=2.82(1.55-5.14)]$ between fever and primary tooth eruption.

Conclusion: There are few suitable studies in the literature regarding the association between primary tooth eruption and fever. However, our study found an association between fever and primary tooth eruption only when rectal temperature was performed

Keywords: Fever, Primary tooth, Tooth eruption.

How to cite this article: Nemezio MA, De Oliveira $\mathrm{KMH}$, Romualdo PC, Queiroz AM, Paula-e-Silva FWG, Silva RAB, Küchler EC. Association between Fever and Primary Tooth Eruption: A Systematic Review and Meta-analysis. Int J Clin Pediatr Dent 2017;10(3):293-298.

\footnotetext{
${ }^{1,2}$ Assistant Professor, ${ }^{3}$ Postdoctoral Researcher, ${ }^{4,6}$ Associate Professor, ${ }^{5,7}$ Research Associate

${ }^{1}$ Department of Dentistry, Tiradentes University, Maceió, Alagoas Brazil

${ }^{2}$ Department of Dentistry, Federal University of Sergipe, Lagarto Sergipe, Brazil

3-7Department of Pediatric Dentistry, University of São Paulo Ribeirão Preto, São Paulo, Brazil

Corresponding Author: Katharina MH De Oliveira, Assistant Professor, Department of Dentistry, Federal University of Sergipe, Lagarto, Sergipe, Brazil, Phone: +551633154057 e-mail: kmho@usp.br
}

\section{Source of support: Nil}

Conflict of interest: None

\section{BACKGROUND}

Tooth eruption is a natural physiological process that consists of the tooth migrating from its intraosseous position in the jaw to appear in the oral cavity. It involves many physiological mechanisms. ${ }^{1}$ The eruption of primary tooth usually begins from 4 to10 months after birth. The full primary dentition with twenty primary teeth is almost always completed in a 30-months-old. ${ }^{2}$ The process of tooth eruption is under strong genetic control with minor influence from environmental factors. ${ }^{3}$

Primary tooth eruption has been associated with some symptoms that include irritability, gingival irritation, increased salivation, restless sleep, diarrhea, loss of appetite, and fever. ${ }^{4-9}$ Among these symptoms, fever is the most frequently reported by mothers ${ }^{7,8,10-13}$ and health care professionals. ${ }^{6,14,15}$

Fever is defined as body temperature above the normal of $98.6^{\circ} \mathrm{F}\left(37^{\circ} \mathrm{C}\right)$. The body temperature measurement is most commonly taken to confirm the presence or absence of fever and it is an important physical sign in many childhood diseases. Many decisions concerning the investigation and treatment of children are based on the results of temperature measurement. To determine the presence of fever in young children is particularly important in order to detect the illness. ${ }^{16-20}$

The issue of symptoms associated with tooth eruption has been controversial; some studies reported that specific symptoms are associated with tooth eruption, while others failed to demonstrated this association. ${ }^{711,20-22}$ This is particularly true in the case of fever. Thus, the aim of this study is to perform a systematic review and metaanalysis to establish if fever is associated with primary tooth eruption.

\section{MATERIALS AND METHODS}

This review was based on Prisma Statement (www. prismastatement.org). The concept of the study was first registered in the international prospective register of systematic reviews, "PROSPERO" (CRD42015019994). 


\section{Search Strategy}

The search strategy was based on the following Medical Subject Heading (MeSH) terms or Text Word [tw] in different combination strategies: "Tooth eruption" [MeSH terms] or "Dental eruption" [tw] or "Primary teeth eruption" $[\mathrm{tw}]$ or "Deciduous tooth eruption" $[\mathrm{tw}]$ and "Fever" [MeSH terms].

The literature searches involved PubMed MEDLINE, Web of Science, Scopus, and Cochrane. The potentially relevant studies had their full texts analyzed and were included since they met all the exclusion criteria in the systematic review.

Two examiners (MAN and KM) evaluated titles, abstracts, and full text and if there was a diverging opinion, the disagreement among examiners was reexamined in consensus meetings with a third examiner (PCR).

\section{Eligibility Criteria and Outcome Measures}

Only studies concerning fever during eruption period of primary tooth in humans were included. Papers in non-English language and papers that included syndromic patients or patients with any systemic disease were excluded.

The review design is presented in Table 1, following the PECO strategy. Only the studies that followed the PECO criteria were included. All studies should measure the body temperature at least once during the primary tooth eruption and at a time that was not associated with tooth eruption.

An assessment of quality and risk of bias of the studies included in the systematic review was performed. The checklist included questions on the study design, sample size calculation, inclusion and exclusion criteria, and statistical analyses. When evaluating the criteria for each study, the reviewers (ECK and MAN) assigned problems for each criterion as low, high, or unclear in terms of their expected effect on the results. The decision was made as to whether the methods were adequate for producing high-quality information.

The meta-analyses were performed using the Review Manager software (version 5.3). Forest plots and summary risk of bias were created with this software. At this stage, only studies that reported the results as dichotomous data were analyzed with Cochran-Mantel-Haenszel test

Table 1: Description of the population exposure comparison and outcome

\begin{tabular}{ll}
\hline Acronym & Description \\
\hline P (population) & Toddler \\
E (exposition) & Primary tooth eruption \\
C (comparison) & Noneruption and during eruption period \\
O (outcome) & Fever \\
\hline
\end{tabular}

in meta-analysis function of Review Manager 5.3. The fixed-effects model was used to evaluate the association between tooth eruption and fever. The pooled odds ratio was used to compare the relative odds of the fever during tooth eruption (confidence interval $=95 \%$ ).

The $\mathrm{I}^{2}$ statistic was used to assess statistical heterogeneity between studies, where $\mathrm{I}^{2}$ values of 25,50 , and $75 \%$ indicated low, medium, and high heterogeneity respectively.

\section{REVIEW RESULTS}

\section{Study Identification and Characteristics}

Flow Chart 1 shows a flow diagram describing the process of studies selection related to fever and primary tooth eruption. Search (until March 2016) at PubMed MEDLINE identified 56 potential studies, the Web of Science search identified 5 potential studies, the Scopus search identified 20, and the Cochrane search identified 2 studies.

After exclusion of the duplicated studies (7), the remaining were analyzed and excluded if the subjects were not related to the proposed by title reading (60) or abstract reading (5). Thus, 56 were excluded because they were not related to the subject, 4 because were in other languages, 1 because it was a review study and 4 because they were case reports.

Eleven studies were followed for full-text analysis. Five studies did not measure fever and evaluated tooth eruption or were based on the parents beliefs or reports and, therefore, were excluded. Thereby, six studies were selected for the systematic review. A summary of the selected was described in Table 2.

\section{Quality Assessment and Risk of Bias}

The quality assessment of the prospective longitudinal studies revealed generally proper reporting and the presence of low or unclear risk of bias (Fig. 1). One case-control study presented a high risk of bias. ${ }^{8}$ Of those, only 2 studies calculated sample size. ${ }^{7,10}$ In two studies, the inclusion and exclusion criteria were satisfactorily described. ${ }^{7,10}$ In all studies, the statistical analysis was satisfactory.

\section{Overall Summary}

The studies performed by Ramos-Jorge et $\mathrm{al}^{10}$ and Wake et $\mathrm{al}^{11}$ were not included in the meta-analyses due the fact that their results were presented as a continuous variable and were unable to be dichotomized. They were also not comparable.

Figure 2 presents the Forest plot for the meta-analysis. In the subgroup analysis, according to the site at the body used to record the temperature, the rectal method presented an association between fever and primary 
Flow Chart 1: Stages of the study selection progression according to Prisma Statement

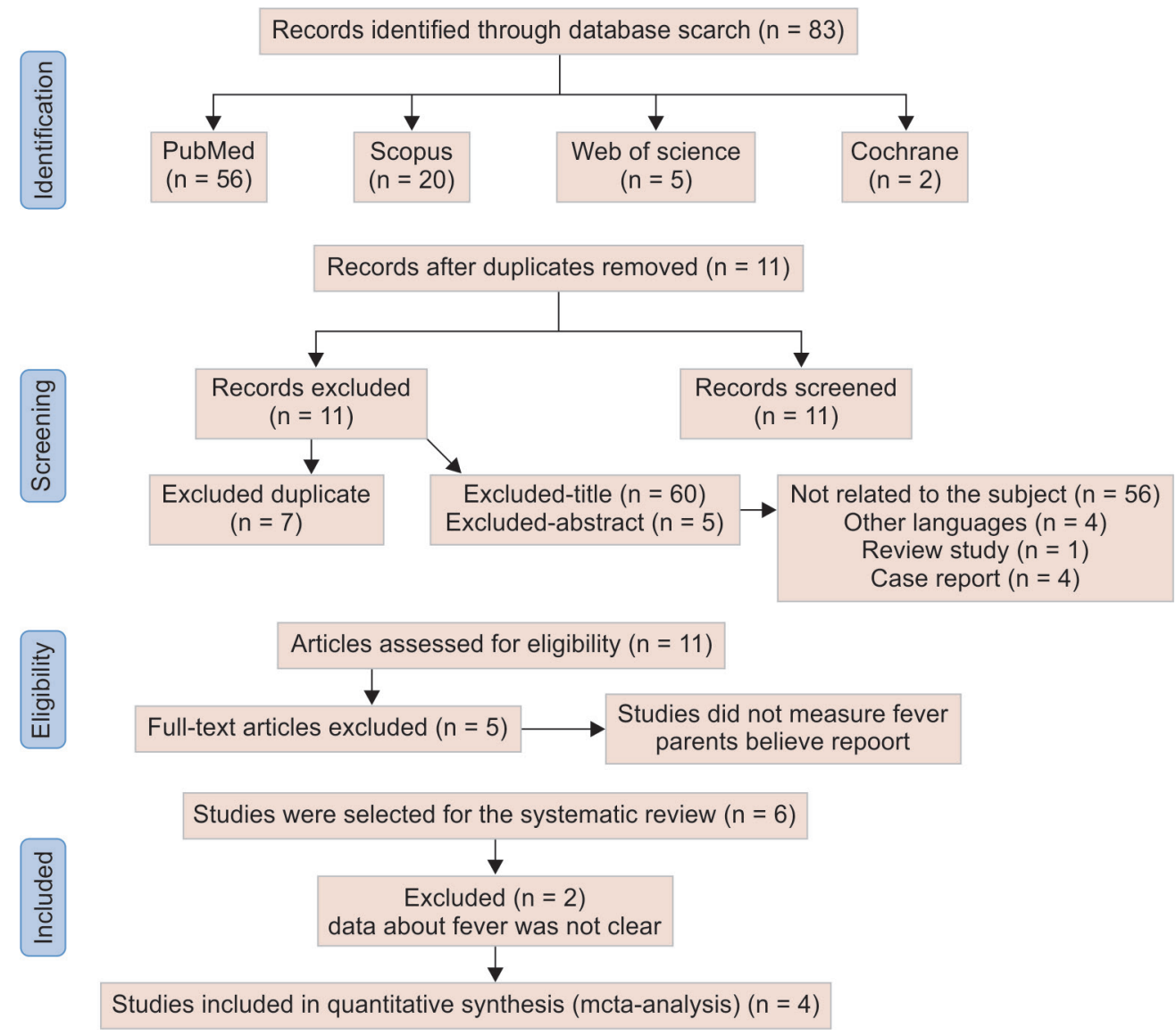

tooth eruption $(\mathrm{OR}=2.82$ [1.55-5.14]). In the overall metaanalyses results, fever was not associated with primary tooth eruption $(\mathrm{OR}=1.32$ [0.88-1.96]). Substantial quantitative heterogeneity was found on the multiplicative scale $\left(\mathrm{I}^{2}=88 \%, \mathrm{p}<0.0001\right)$.

\section{DISCUSSION}

Previous studies have attempted to evaluate body temperature alteration as a sign associated with primary tooth eruption. However, this issue is still unclear in pediatric research. Although many studies reported this association, our meta-analyses were not able to confirm this. Our results could probably be influenced by the heterogeneity among the studies included in the meta-analyses.

Different sites on the body can be used to record the body temperature. In addition, different thermometers, such as mercury-in-glass and liquid-in-glass, electronic with digital display, infrared or tympanic, contact or noncontact temporal artery thermometer, or disposable chemical thermometers are devices commonly used in young children. ${ }^{18}$ The included studies had different methods to detect fever.

In studies that used the rectal temperature, there was an association between fever and tooth eruption ${ }^{12,13}$ and our meta-analysis of the pooled results of these two studies confirmed that fever is almost three times more common in the primary eruption period. The studies that used axillary and tympanic temperatures also found an association between fever and tooth eruption. ${ }^{10}$ Interestingly, the three studies, in which the type of method to detect fever was not clear, ${ }^{8}$ did not find association between these two conditions. In fact, previous studies showed that measurement of temperature by ear thermometer was less accurate than rectal temperature. ${ }^{23-25}$ This may explain our meta-analysis results.

Many studies in the literature attempting to compare rectal, oral, tympanic, and axillary thermometers have been conducted to find the most appropriate thermometer and the best anatomical site for temperature measurement. ${ }^{16,26-31}$ Axillary thermometry is less invasive, but does not reflect core temperature and it is largely influenced by ambient temperature and vasoactivity. ${ }^{26}$ Rectal temperature is about $1^{\circ} \mathrm{F}\left(0.5^{\circ} \mathrm{C}\right)$ higher than an oral temperature and $2^{\circ} \mathrm{F}\left(1^{\circ} \mathrm{C}\right)$ higher than an axillary temperature. $^{32}$

Another concern that may be considered is the subject who performed the temperature measurements. It has been reported in literature that readings of temperature obtained by parents differ from those obtained by a nurse using the same instrument by a clinically 


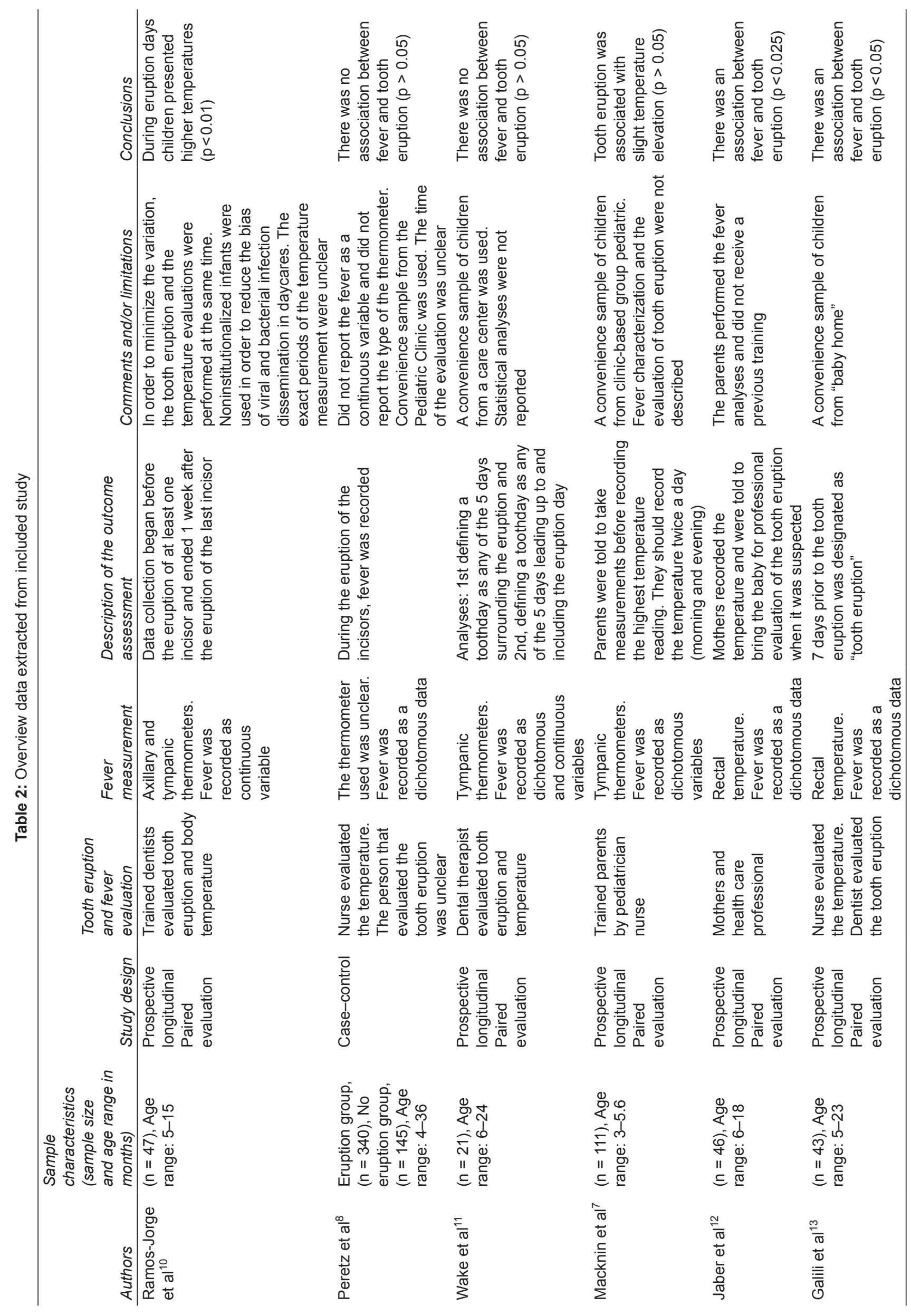




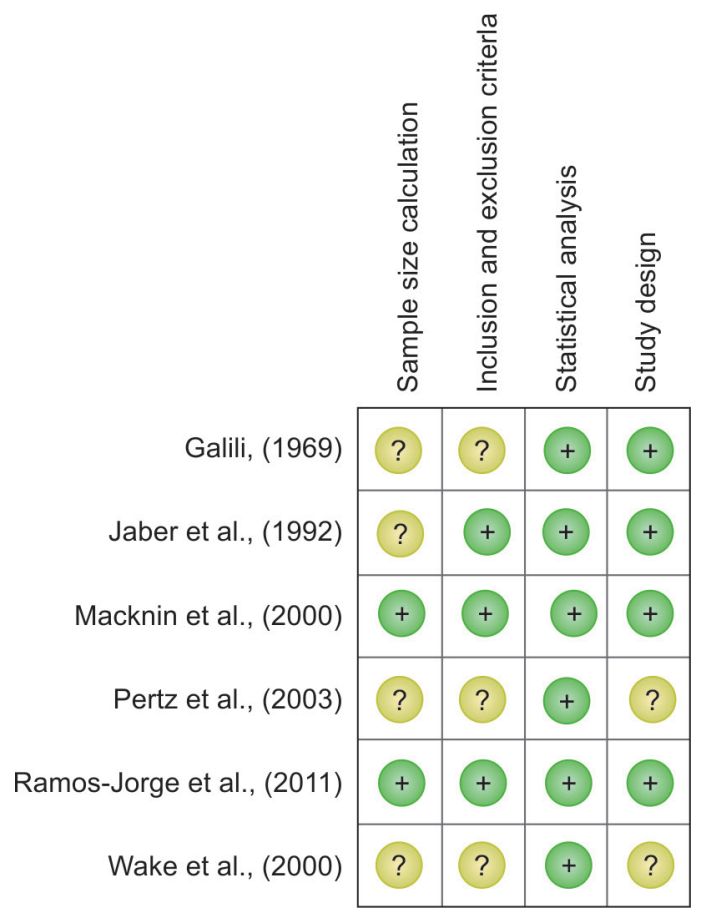

Fig. 1: Quality assessment of the included studies (The Cochrane Collaboration tool for assessing risk of bias)

significant amount $\left(0.5^{\circ} \mathrm{C}\right.$ or more $){ }^{33}$ The sample selection can also influence the outcome. Some studies investigated samples with low risk of bias. ${ }^{34,35}$ In addition, the outcome assessment was different according to the study design and might also influence the final result of this meta-analyses.

Only three studies fully described the inclusion and exclusion criteria. They attempted to report the characteristics and health condition of the included children. ${ }^{7,10,11}$ The other 3 studies only reported gender and age. $8,12,13$

\section{CONCLUSION}

In conclusion, there are few suitable studies in the literature regarding the association between primary tooth eruption and fever. However, our study found an association between fever and primary tooth eruption only when rectal temperature was performed. Therefore, we believe that further studies should be conducted to shed light on this relationship using different methods for measurement of body temperature.

\section{CLINICAL SIGNIFICANCE}

Primary tooth eruption has been associated with several symptoms, and fever is the most frequent one reported by mothers and health care professionals. The issue of symptoms during tooth eruption is controversial and it is very important not to underestimate the presence of fever during teething, ensuring that it is not due to other infections.

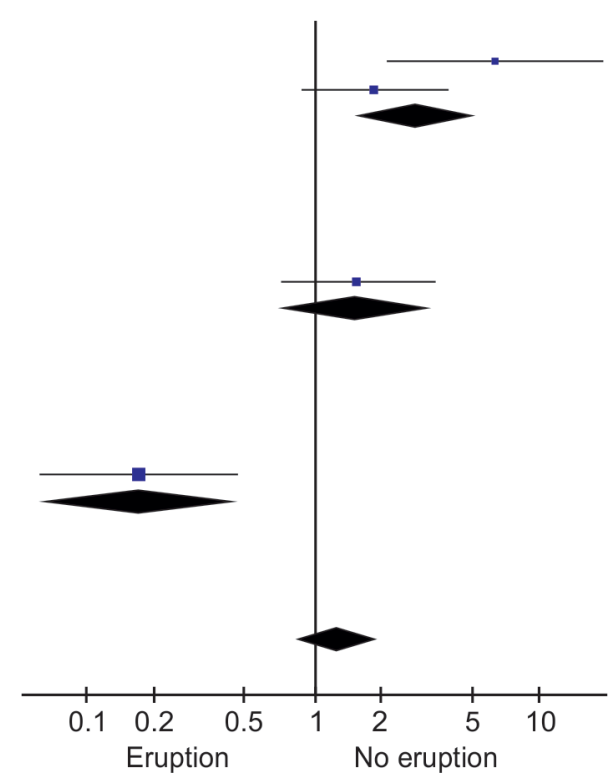

Fig. 2: Forest plot

\section{REFERENCES}

1. Massier M, Schour I. Studies in tooth development: theories of eruption. Am J Orthod 1941 Oct;27(10):522-576.

2. Baykan Z, Sahin F, Beyazova U, Ozçakar B, Baykan A. Experience of Turkish parents about their infants' teething. Child Care Health Dev 2004 Jul;30(4):331-336.

3. Lloyd S. Teething in babies: separating fact from fiction. Prof Care Mother Child 1996;6(6):155-6.

4. Seward MH. Local disturbances attributed to eruption of the human primary dentition. A survey. Br Dent J 1971 Jan;130(2):72-77.

5. Seward MH. General disturbances attributed to eruption of the human primary dentition. ASDC J Dent Child 1972 MayJun;39(3):178-183.

6. Coreil J, Price L, Barkey N. Recognition and management of teething diarrhea among Florida pediatricians. Clin Pediatr (Phila) 1995 Nov;34(11):591-598.

7. Macknin ML, Piedmonte M, Jacobs J, Skibinski C. Symptoms associated with infant teething: a prospective study. Pediatrics 2000 Apr;105(4):747-752.

8. Peretz B, Ram D, Hermida L, Otero MM. Systemic manifestations during eruption of primary teeth in infants. J Dent Child (Chic) 2003 May-Aug;70(2):170-173.

9. Cunha RF, Pugliesi DM, Garcia LD, Murata SS. Systemic and local teething disturbances: prevalence in a clinic for infants. J Dent Child (Chic) 2004 Jan-Apr;71(1):24-26.

10. Ramos-Jorge J, Pordeus IA, Ramos-Jorge ML, Paiva SM. Prospective longitudinal study of signs and symptoms associated with primary tooth eruption. Pediatrics 2011 Sep;128(3): 471-476.

11. Wake M, Hesketh $\mathrm{K}$, Lucas J. Teething and tooth eruption in infants: a cohort study. Pediatrics 2000 Dec;106(6):1374-1379.

12. Jaber L, Cohen IJ, Mor A. Fever associated with teething. Arch Dis Child 1992 Feb;67(2):233-234.

13. Galili G, Rosenzweig KA, Klein H. Eruption of primary teeth and general pathologic conditions. ASDC J Dent Child 1969 Jan;36(1):51-54.

14. Ige OO, Olubukola PB. Teething myths among nursing mothers in a Nigerian community. Niger Med J 2013 Mar;54(2):107-110. 
15. Ispas RS, Mahoney EK, Whyman RA. Teething signs and symptoms: persisting misconceptions among health professionals in New Zealand. N Z Dent J 2013 Mar;109(1):2-5.

16. Carr EA, Wilmoth ML, Eliades AB, Baker PJ, Shelestak D, Heisroth KL, Stoner KH. Comparison of temporal artery to rectal temperature measurements in children up to 24 months. J Pediatr Nurs 2011 Jun;26(3):179-185

17. Al-Mukhaizeem F, Allen U, Komar L, Naser B, Roy L, Stephens D, Read S, Kim C, Schuh S. Comparison of temporal artery, rectal and esophageal core temperatures in children: results of a pilot study. Paediatr Child Health 2004 Sep;9(7):461-465.

18. El-Radhi AS. Determining fever in children: the search for an ideal thermometer. Br J Nurs 2014 Jan-Feb;23(2):91-94.

19. Caspe WB, Chamudes O, Louie B. The evaluation and treatment of the febrile infant. Pediatr Infect Dis 1983 MarApr;2(2):131-135.

20. McCarthy PL, Sharpe MR, Spiesel SZ, Dolan TF, Forsyth BW, DeWitt TG, Fink HD, Baron MA, Cicchetti DV. Observation scales to identify serious illness in febrile children. Pediatrics 1982 Nov;70(5):802-809.

21. McIntyre GT, McIntyre GM. Teething troubles? Br Dent J 2002 Mar;192(5):251-255.

22. Ashley MP. It's only teething....a report of the myths and modern approaches to teething. Br Dent J 2001 Jul;191(1):4-8.

23. Odinaka KK, Edelu BO, Nwolisa CE, Amamilo IB, Okolo SN. Temporal artery thermometry in children younger than 5 years: a comparison with rectal thermometry. Pediatr Emerg Care 2014 Dec;30(12):867-870.

24. Allegaert K, Casteels K, van Gorp I, Bogaert G. Tympanic, infrared skin, and temporal artery scan thermometers compared with rectal measurement in children: a real-life assessment. Curr Ther Res Clin Exp 2014 May;76:34-38.

25. Oncel MY, Tekgunduz KS, Ozdemir R, Calisici E, Karahan S, Erdeve O, Oguz SS, Dilmen U. A comparison of different methods of temperature measurement by mothers and physi- cians in healthy newborns. Indian J Pediatr 2013 Mar;80(3): 190-194.

26. Bernardo LM, Henker R, O'Connor J. Temperature measurement in pediatric trauma patients: A comparison of thermometry and measurement routes. J Emerg Nurs 1999 Aug;25(4):327-329.

27. Barton SJ, Gaffney R, Chase T, Rayens MK, Piyabanditkul L. Pediatric temperature measurement and child/parent/nurse preference using three temperature measurement instruments. J Pediatr Nurs 2003 Oct;18(5):314-320.

28. Khorshid L, E er I, Zaybak A, Yapucu U. Comparing mercuryin-glass, tympanic and disposable thermometers in measuring body temperature in healthy young people. J Clin Nurs 2005 Apr;14(4):496-500.

29. Duran R, Vatansever U, Acuna B, Süt N. Comparison of temporal artery, mid-forehead skin and axillary temperature recordings in preterm infants $<1500 \mathrm{~g}$ of birthweight. J Paediatr Child Health 2009 Jul-Aug;45(7-8):444-447.

30. Titus MO, Hulsey T, Heckman J, Losek JD. Temporal artery thermometry utilization in pediatric emergency care. Clin Pediatr (Phila) 2009 Mar;48(2):190-193.

31. Fortuna EL, Carney MM, Macy M, Stanley RM, Younger JG, Bradin SA. Accuracy of non-contact infrared thermometry versus rectal thermometry in young children evaluated in the emergency department for fever. J Emerg Nurs 2010 Mar;36(2):101-104.

32. Canales AE. OTC device: temporal scanner TAT-2000C. J Am Pharm Assoc (2003) 2007 Jan-Feb;47(1):112.

33. Robinson JL, Jou H, Spady DW. Accuracy of parents in measuring body temperature with a tympanic thermometer. BMC Fam Pract 2005 Jan;6(1):3.

34. Gensheimer KF. A public health perspective on child care. Pediatrics 1994 Dec;94(6 Pt 2):1116-1118.

35. Louhiala PJ, Jaakkola N, Ruotsalainen R, Jaakkola JJ. Form of day care and respiratory infections among Finnish children. Am J Public Health 1995 Aug;85(8 Pt 1):1109-1112. 